\title{
Ethnic Residential Segregation in the United Kingdom by Age Group: the Case of Bradford
}

\author{
David McEvoy
}

\begin{abstract}
There is a long running debate on the significance of ethnic residential segregation levels in Britain. These phenomena have been related to the extent of community cohesion in British cities, and particularly to the riots of 2001 in the north of England. Further light is cast on these issues by examining ethnic segregation by age in the case of Bradford, the location of the largest riot. Both the dissimilarity index and the exposure index are used to consider relations between the White British and the largest minorities at ward level and at census output area level. The level of segregation is shown to vary with age, usually in a consistent direction. The direction varies between ethnic groups however.
\end{abstract}

\section{Introduction}

In the summer of 2001 a series of riots erupted across the north of England. The Denham and Cantle Reports to national government on these events identified a lack of community cohesion as a contributory factor (Home Office 2001a, p. 119, 2001b). The Cantle Report identified ‘the depth of polarisation’ between ethnic communities as a major context of disorder: 'the physical segregation of housing estates and inner city areas ... compounded by so many other aspects of our daily lives, was very evident. Separate educational arrangements, community and voluntary bodies, and employment, places of worship, language, social and cultural networks, means (sic) that many communities operate on the basis of a series of parallel lives. These lives do not seem to touch at any point, let alone overlap and promote any meaningful interchanges' (Home Office 2001b, p. 9). Ignorance of other communities grows into fear, which is exploited by extremist groups.

Both Cantle and Denham drew on Ouseley, a report for Bradford City Council, as evidence of the segregated situation in Bradford (Ouseley 2001). It appeared to confirm that community relations in the city were dangerously polarised: 'communities are fragmenting on racial, cultural and faith lines ... intolerance towards differences is growing' (2001, p. 6). Both 'white flight' and 'self-segregation' were identified as contributors to this situation (2001, pp. 9-10). 'different ethnic groups in Bradford are increasingly segregating themselves from each other and retreating into “comfort zones” made up of people like themselves’ (2001, p. 16). 
Alexander (2005) argues that these reports 'placed the origin of the disturbances in ethnic and racial segregation and cultural difference'. Similarly, Fortier (2007) observes that British public policy discourse more generally understands community cohesion in a localised way: mixing between ethnic groups requires spatial proximity. Community cohesion can thus perhaps be understood as a geographically defined version of social cohesion. Neither Alexander nor Fortier endorses this spatial interpretation of riot causation. Indeed Alexander accuses the reports of ignoring the effects of historical context, structural inequalities, deindustrialisation, racial discrimination, far right political activism, racist attacks and police harassment. Other authors have amplified many of these other factors (Amin 2003; Husan 2003; Kundnani 2001; McGhee 2003; Renton 2003; Webster 2003).

Simpson (2004) is perhaps the most sceptical critic on the role of segregation. He is particularly critical of Ouseley's identification of 'the legend' of self-segregation, and of its repetition in government reports and news items. This legend used racialised language: 'Flight' is the term used to describe White movement, while 'selfsegregation' is reserved for other groups (2004, p. 677). ‘[I]t is not the geography but the analysis which is racially patterned' (2004, p. 679).

Despite these objections there are however grounds for affording spatial demographic patterns some role in the analysis of the riots. The largest riot occurred in Bradford on July $7^{\text {th }}$. Most of the rioters involved were young Muslim men of Pakistani ancestry, in their teens and twenties. Many were arrested on the basis of video evidence captured by the police. Following trial and conviction substantial prison sentences were imposed (Allen 2003). The columns of the Bradford daily newspaper, the Telegraph and Argus saw a flood of letters approving of the punishments. The names of the signatories and the content of the letters allow the reasonable inference that most of these correspondents were whites of middle age and older. Moreover the addresses of the convicted rioters and of the letter writers indicate a distinct geographical pattern, with the former residing in inner urban areas, and their critics in the immediately surrounding areas (McEvoy 2007). 
This not only supports the official diagnosis of poor community cohesion, but also raises the question of whether age is an exacerbating factor in increasing segregation and limiting contact across the ethnic divide. Teenagers do not normally spend their leisure time with older age groups. Most older people are gratified that this is so, and prefer to associate with their contemporaries. Each generation makes most of its friends among people of broadly similar age, and patronises stores, bars, restaurants and events where its tastes are catered for. In situations where society is already segregated by ethnicity it may be that age-differentiated migration patterns produce situations where members of an ethnic group find that most of their neighbours of another ethnic group are the wrong age for social interaction to be likely.

Burgess and Wilson (2003) showed that in much of Britain schools are not ethnically mixed. They also linked the riots to high levels of ethnic segregation. They suggested that the riots occurred in urban areas where the segregation of South Asian pupils was highest according to the two types of segregation measure discussed below. In conjunction with a co-author they later moderated this claim, and noted that the coincidence of rioting and high segregation levels is not complete, since there were no riots in Leicester, a city with comparable segregation levels. They were however able to demonstrate that the concentration of non-whites in schools is at least six times greater than would be expected on the basis of a random allocation across schools in their Local Education Authority (Johnston, Wilson \& Burgess 2004).

\section{Bradford}

Bradford is a city with a long history of immigration. In the nineteenth century considerable numbers of Irish, Jews and Germans arrived as wool textile manufacturing boomed. After the Second World War east European refugees were welcomed as a cheap and compliant labour force, and recruitment was then extended to the Indian sub-continent, particularly Pakistan (Jackson 1992). This attempt to shore up a declining industry failed in the face of global competition. Chain migration and high birth rates have nevertheless built up a substantial population of Pakistani origin in the city, with smaller communities from India and Bangladesh. Table 1 shows that by 200114.5 per cent of residents were ethnically Pakistani, with 2.7 per cent Indian and 1.1 per cent Bangladeshi. The 'Other White' group, including the 
city's east Europeans, makes up 1.5 per cent of the total, and the White British majority 76.0 per cent. A variety of other minorities constitute the remaining 4.2 per cent.

\section{Table 1.}

The population of Bradford by ethnic group 2001

White British
White Irish
White Other
Mixed White \& Black Caribbean
Mixed White \& Black African
Mixed White \& Asian
Mixed Other
Indian
Pakistani
Bangladeshi
Asian Other
Black Caribbean
Black African
Black Other
Chinese
Other Ethnic Group

Not White British

Total

$\begin{array}{rr}\text { No. } & \text { \% } \\ 355684 & 76.0 \\ 3499 & 0.7 \\ 6855 & 1.5 \\ 2636 & 0.6 \\ 478 & 0.1 \\ 2932 & 0.6 \\ 950 & 0.2 \\ 12479 & 2.7 \\ 67977 & 14.5 \\ 4953 & 1.1 \\ 2971 & 0.6 \\ 3062 & 0.7 \\ 987 & 0.2 \\ 321 & 0.1 \\ 885 & 0.2 \\ 1035 & 0.2 \\ & \\ 112020 & 24.0 \\ & \\ 467704 & 100.0\end{array}$

Source for data used in all tables: Census 2001. Census output is Crown copyright and is reproduced by permission of the Controller of HMSO and the Queen's Printer for Scotland

Within Bradford the ethnic geography is very uneven. The 30 wards vary between 22.9 per cent White British in the inner-city University ward to 96.8 per cent in peripheral Craven. Among the 1457 output areas identified by the census the variation is from 100 per cent White British in 26 localities to 2.9 per cent. The latter is also the output area with the highest proportion of Pakistanis, 89.4 per cent. In contrast 557 output areas, 38 per cent of the city, have no Pakistanis whatsoever. When the population is differentiated by age as well as ethnicity the marginal statistics become even more extreme. At ward level in Ilkley 95.4 per cent of the under-5s are White British, and 98.3 per cent of those 75 or older. In University ward only 6.2 per cent of 
the under-5s are White British, and only 52.9 per cent of the over-75s. On the output area scale 644 vicinities, 44.2 per cent of the total, are entirely White British among under-5s. Meanwhile 52 output areas have no White British children under 5. There are also 937 output areas, 64.3 per cent, with no Pakistanis aged 0-4, and 11 output areas where all of this age group are Pakistanis. There are also 9 output areas where all of the over-75s are Pakistani, and 1275 (87.5 per cent) where there are no Pakistanis of this age. 909 areas are 100 per cent White British among over 75s, while 44 areas have no over-75 White British.

\section{Segregation Measures}

The two most common measures used in studies of ethnic segregation are the dissimilarity index (ID), and the exposure index ( $\mathrm{p}^{*}$ ), also referred to as the isolation, interaction or probability index. The dissimilarity index measures the proportion of an ethnic group which would have to move to another spatial unit in order to match the geographical distribution of another ethnic group. If all of a city's minority population reside in a single quarter, and none of the majority population live there, then the two populations are totally segregated from one another, and the dissimilarity index has a value of 100 , indicating that either the minority population or the majority population would have to totally relocate in order to match the spatial pattern of the other group. If on the other hand the index has a value of zero this is an indication that the two populations under review exactly match each other's geographical distribution. The dissimilarity index is sometimes scaled to run from 0.00 to 1.00 .

Many studies compare the distribution of a particular minority with that of the rest of the population, a version of the dissimilarity index known as the segregation index (Peach \& Rossiter 1996, p. 119). In this paper the dissimilarity index is used mainly to compare the distribution of minorities with that of the White British, the dominant ethnic group of the United Kingdom, and of Bradford. In this way each minority is compared with the same set of figures, rather than with a rest of the population which differs for each minority. We will therefore be studying the segregation of ethnic minorities in a standardised fashion. 
Many ethnic minorities in Britain are continuing to grow, as a result of both continued immigration and natural increase, the latter being a consequence of relatively youthful age structures (table 2). One implication of growth in the same areas is that over time the typical member of a minority finds that more of his or her neighbours are from the same ethnic group. Concurrently the same individual finds that the proportion of whites in the neighbourhood is falling. This experience is captured by the exposure index. The idea of this statistic is that it captures the asymmetric experience of segregation in a way that the dissimilarity index does not. Let us consider a relatively small group such as Black Caribbeans (0.7 per cent of Bradford's population) in comparison with a much larger group such as the White British (76.1 per cent). The dissimilarity index gives us a single measure indicating that 42.5 per cent of either group would have to move wards for that group to match the distribution of the other. For most of the White British this means that they live in areas in which Black Caribbeans are a small minority. In contrast most Black Caribbeans find that they live in areas where the White British are by far the largest group. The $\mathrm{p}^{*}$ index records this differential experience. Black Caribbeans find that on average 65.4 per cent of their ward's residents are White British, whereas the White British find that on average only 0.6 per cent of their ward's population is Black Caribbean.

\section{Table 2}

\section{Age structure of ethnic groups in Bradford}

\begin{tabular}{|c|c|c|c|c|c|c|}
\hline $\begin{array}{l}\text { Age } \\
\text { groups }\end{array}$ & $\begin{array}{c}\text { All } \\
\text { people }\end{array}$ & $\begin{array}{l}\text { White } \\
\text { British }\end{array}$ & $\begin{array}{l}\text { White } \\
\text { Other }\end{array}$ & Indian & Pakistani & Bangladeshi \\
\hline $0-4$ & 7.1 & 5.7 & 3.1 & 7.5 & 13.5 & 16.1 \\
\hline $5-15$ & 14.8 & 13.1 & 6.1 & 15.6 & 22.3 & 24.2 \\
\hline $16-29$ & 20.5 & 17.7 & 19.9 & 26.7 & 32.2 & 33.6 \\
\hline $30-49$ & 27.6 & 28.7 & 26.7 & 30.8 & 22.1 & 17.6 \\
\hline $50-74$ & 23.3 & 26.6 & 28.0 & 17.5 & 9.0 & 8.0 \\
\hline $75+$ & 6.7 & 8.2 & 16.1 & 1.8 & 1.0 & 0.5 \\
\hline Total & 100.0 & 100.0 & 99.9 & 99.9 & 100.1 & 100.0 \\
\hline
\end{tabular}

A useful way of thinking about the exposure index is to consider it as the average percentage of one ethnic group in each spatial unit, weighted by the spatial unit's share of a second ethnic group in the whole city. This defines the chances of the second ethnic group finding that its co-residents in a spatial unit are from the first 
group. Those who are unfamiliar with this measure will find a succinct technical explanation in Peach and Rossiter (1996, p. 126). Like the dissimilarity index the exposure index can be scaled to run from 0 to 100 , or from 0.00 to 1.00 . As with the dissimilarity index, many of the exposure index values reported in this paper relate to comparisons between other groups and the White British. Some comparisons are however made between Pakistanis and other groups.

An important feature of the dissimilarity measure is that its value increases as the size of the geographical areas used in its calculation decreases. The differences between ethnic population distributions at ward level are still present if the data are reexamined at a finer scale, such as the output areas used by the British census, but these smaller areas add more detail, which adds to the measure of unevenness between the distributions. It is worth emphasising however that most of the segregation measured by an output area index is already captured by the ward level index. For example in the case of Bradford the ward level dissimilarity index between the White British and Indians is 53.4, and the output area value is 66.8. Since there are 30 wards in the city, but 1457 output areas, an almost 5000 per cent increase in the number of spatial units adds only 25 per cent to the segregation measure. The exposure measure does not always change in a consistent manner with scale, as we will see below.

Given that most of the segregation measures in this paper are reported at both the ward and output area scales, it is important to avoid including groups in the analysis which were so small that part of the measured segregation might be the result of their being too few group members to allow their distribution across all areas. Since the majority of the population live in a family or household of more than one member it was decided to confine the analysis to groups with populations which exceed the number of output areas by a minimum of three. By coincidence this criterion identifies those groups amounting to more than 1.0 per cent of the population. The groups selected are therefore: White British, Pakistani, Indian, Other White and Bangladeshi. (Members of other particular ethnic groups are included in the calculations when either the total population, or the total population which is not White British, is referred to). 


\section{Age and Ethnic Dissimilarity}

A first step in examining the impact of age on ethnic segregation was to establish whether age groups are in fact spatially segregated from one another. This is demonstrated in table 3. It is confined to comparing, by means of the dissimilarity index, those aged 0-9 in each of six ethnic groups with those of successively higher ten-year age bands. The calculations have however been completed for all ethnic groups and all decadal pairs, and the 0-9 figures are not in any way atypical. The first column of values shows the situation for the population as a whole. The dissimilarity in ward level distribution between children aged 0-9 and 10-19 year-olds is only 3.4. As 0-9 year-olds are compared with each higher age group the dissimilarity value generally increases, reaching a maximum of 18.1 for the comparison with those aged over 80. This implies a theoretical redistribution of young children ranging between 3.4 per cent and 18.1 per cent if the distribution of other age groups were to be matched.

\section{Table 3.}

Selected ward level dissimilarity indexes by age group. Bradford 2001

\begin{tabular}{|c|c|c|c|c|c|c|}
\hline Age groups & $\begin{array}{c}\text { All } \\
\text { people }\end{array}$ & $\begin{array}{l}\text { White } \\
\text { British }\end{array}$ & $\begin{array}{l}\text { White } \\
\text { Other }\end{array}$ & Indian & Pakistani & Bangladeshi \\
\hline $0-9: 10-19$ & 3.4 & 3.2 & 26.4 & 14.5 & 3.0 & 11.1 \\
\hline $0-9: 20-29$ & 6.2 & 7.6 & 36.7 & 12.5 & 3.3 & 4.8 \\
\hline 0-9:30-39 & 10.5 & 4.5 & 15.6 & 7.8 & 4.2 & 10.4 \\
\hline $0-9: 40-49$ & 17.4 & 8.6 & 22.3 & 13.9 & 5.2 & 15.1 \\
\hline 0-9:50-59 & 17.4 & 8.8 & 22.1 & 12.7 & 5.3 & 13.8 \\
\hline $0-9: 60-69$ & 14.3 & 8.9 & 28.6 & 16.2 & 8.6 & 11.6 \\
\hline 0-9:70-79 & 15.8 & 9.7 & 28.9 & 23.4 & 8.0 & 25.0 \\
\hline 0-9: 80+ & 18.1 & 13.7 & 30.3 & 30.4 & 14.0 & 73.1 \\
\hline
\end{tabular}

The same general pattern of increasing segregation as 0-9 year-old are compared with successively older cohorts is repeated for each of the specific ethnic groups covered by the table. No attempt is made to explain the lower values for the White British and Pakistanis, and the higher values for the other three groups. The point is to establish that age groups are somewhat segregated from one another both within ethnic groups and in the total population. 
It can be seen by comparison with table 4 that dissimilarity index values between age groups are generally lower than between ethnic groups measured at the same scale. The first column of table 4 gives the index values between the White British and the other selected groups at ward scale. White Others have the lowest dissimilarity with the White British at both scales. Indians are next in order of segregation, then Pakistanis, and finally Bangladeshis. For the latter the output area figure indicates that 89 per cent of Bangladeshis would need to live elsewhere if they were to match the distribution of the White British population.

\section{Table 4}

\section{Dissimilarity from White British for selected ethnic groups. Bradford 2001}

$\begin{array}{lcc}\text { White Other } & \begin{array}{c}\text { Output } \\ \text { areas }\end{array} \\ \text { Indian } & 23.9 & 40.1 \\ \text { Pakistani } & 53.4 & 66.8 \\ \text { Bangladeshi } & 63.6 & 79.9 \\ & 69.7 & 89.4\end{array}$

Although it is an attractive idea to analyse ethnic population data in terms of the 10year age cohorts used above, it proves impossible to do so in practice at both the geographical scales reported by the census. Because the average output area contains only 321 residents there is a risk that if too many census variables were to be crosstabulated information about individuals might be revealed. As one of the measures adopted to eliminate this risk the census only reports ethnic group populations at output area level in seven age bands: 0-4, 5-15, 16-29, 30-49, 50-retirement age, retirement age to 75, and 75 plus. Retirement age is not the same for men and women. It is 65 for men but 60 for women. Categories with different age boundaries for men and women are not clearly the best for examining age segregation. The seven categories have therefore been reduced to six for the purposes of this paper by creating a 50-75 age group. In order to permit comparisons across scales the ward level data, although available in much finer age detail, has been aggregated to these six categories. 
The interaction of age and ethnicity is introduced in table 5. This table reports dissimilarity values within age groups. Unlike table 3 it does not examine relationships between age groups. So in the first cell of the White Other column the figure of 31.1 indicates that this is the percentage of White Others under five who would have to change ward if they were to match the geographical distribution of White British under-fives. In the upper part of the table, covering the ward level computations, two clear features appear. First, the pattern of segregation revealed in table 4 is repeated in the individual age bands. Dissimilarity from the White British is lower in every age group for the White Others, followed by Indians, Pakistanis and Bangladeshis.

\section{Table 5}

Dissimilarity from White British by age group. Bradford 2001.

\section{Wards}

$\begin{array}{lccccc}\text { Age groups } & \begin{array}{c}\text { White } \\ \text { Other }\end{array} & \text { Indian } & \text { Pakistani } & \text { Bangladeshi } & \begin{array}{c}\text { All not } \\ \text { White } \\ \text { British }\end{array} \\ \mathbf{0 - 4} & 31.1 & 53.6 & 64.8 & 71.3 & 57.4 \\ \mathbf{5 - 1 5} & 24.6 & 55.6 & 65.2 & 70.5 & 56.1 \\ \mathbf{1 6 - 2 9} & 39.3 & 49.9 & 59.2 & 65.8 & 53.2 \\ \mathbf{3 0 - 4 9} & 18.2 & 51.8 & 64.1 & 68.1 & 50.2 \\ \mathbf{5 0 - 7 4} & 22.7 & 57.8 & 66.9 & 74.7 & 46.1 \\ \mathbf{7 5 +} & 30.6 & 55.5 & 64.8 & 86.0 & 34.9 \\ & & & & & \\ \text { All ages } & 23.9 & 53.4 & 63.6 & 69.7 & 52.4\end{array}$

\section{Output areas}

$\begin{array}{lccccc}\text { Age groups } & \begin{array}{c}\text { White } \\ \text { Other }\end{array} & \text { Indian } & \text { Pakistani } & \text { Bangladeshi } & \begin{array}{c}\text { All not } \\ \text { White } \\ \text { British }\end{array} \\ \mathbf{0 - 4} & 94.5 & 88.3 & 80.0 & 95.1 & 70.8 \\ \mathbf{5 - 1 5} & 89.0 & 79.0 & 81.0 & 94.6 & 69.8 \\ \mathbf{1 6 - 2 9} & 82.1 & 74.3 & 80.1 & 93.1 & 72.5 \\ \mathbf{3 0 - 4 9} & 61.9 & 66.7 & 79.2 & 94.2 & 61.5 \\ \mathbf{5 0 - 7 4} & 65.7 & 79.2 & 83.1 & 97.5 & 58.2 \\ \mathbf{7 5 +} & 81.5 & 95.8 & 93.7 & 99.8 & 69.2 \\ & & & & & \\ \text { All ages } & 40.1 & 66.8 & 79.9 & 89.4 & 65.7\end{array}$


The second clear feature is the falling level of segregation with age when the contrast between the White British and all others combined ('All not White British') is examined. For under-4s the dissimilarity index is 57.4, but the figure declines for each successively older cohort, reaching 34.9 for the over-75s. When the figures for individual ethnic groups are examined however there is an apparent tendency for the higher age groups to display higher dissimilarity figures, the reverse of the general case. Remembering that the specific groups in the table are much larger than those not listed, we cannot attribute this seeming paradox to the statistical influence of unreported data. In any case these figures have been calculated, and with the exception of the Irish, show the same puzzling contrast with their collective trend. A possible explanation may lie in the segregation of these groups from each other. To the extent that these ethnic minorities locate in somewhat different parts of the city from one another, and that their component age groups are somewhat separate from one another (table 3), it would seem that their collective dissimilarity from the White British distribution disaggregates into specific group components differentially across age bands.

The need for such an explanation is however rendered questionable when the lower, output area, portion of table 5 is considered. The column for all groups not White British is utterly devoid of trend, and although the over-75s have the highest figure for three of the four specific groups, it is difficult to interpret this as an age-related trend in any of the cases. The ward level sequence of ethnic groups within age bands also disappears in the output area data. Although the Bangladeshis retain their position as the most segregated group at every age, the order of the other three ethnicities seems completely random. This is probably connected to the very low average numbers per output area for White Others, Indians and Bangladeshis. Even for Indians the average figure is only 8.6, and for White Others and Bangladeshis 4.7 and 3.4. When these small numbers are spread across six age bands it becomes clear that the very high dissimilarity figures for these groups are largely the product of the very large number of output areas where the presence of these groups is necessarily zero. It is sensible to conclude that the dissimilarity figures at ward level are more robust than those at output area level. 
Low numbers per output area may also explain an intriguing feature of the output area figures in table 5: the level of the dissimilarity figures in the all ages row are generally well below the figures for their component ages. In the Bangladeshi and White Other columns the all age figures are lower than any of the specific age figures, very much lower in the White Other case. This feature does not apply to the more reliable ward figures.

\section{Age and Ethnic Exposure}

When we turn to examining exposure indexes the problem of large numbers of zeros at output area level does not recur. If for example we are calculating the exposure of the White British to Bangladeshis or the exposure of Bangladeshis to the White British, the only places entering the calculations are those where both some White British and some Bangladeshis live. Places where one, or theoretically both, groups are absent do not influence figures representing the two groups chances of interacting.

There are five sets of exposure indices reproduced: the exposure of the White British to their own group and to other groups; the exposure of other groups to the White British; the exposure of Pakistanis to their own group and to other groups; the exposure of other groups to Pakistanis; and the exposure of each group to itself (tables 5-9). In order to keep the tables easily comparable some figures are replicated in three tables: for example the White British column in table 6 is the same as the White British column in table 7 and table 10.

\section{Exposure of the White British}

Table 6 examines the chances the White British have of sharing their geographical unit with members of other groups. The upper set of figures describes the situation when wards are the geographical units in question, and the lower set of figures when output areas are considered. Clearly the figures for the exposure of the White British to their own group are very much higher than those indicating their exposure to other groups. For all ages combined, and on average, the White British share their ward with a population which is over 83 per cent White British, not quite 9 per cent Pakistani, and some small percentages of White Others, Indians, Bangladeshis, and smaller groups not tabulated. 
When we turn to the figures for specific age groups at ward level we find considerable variation around the all age averages. The youngest White British children see that about 76 per cent of their contemporaries are White British, but the over-75s have neighbours who are almost 93 per cent White British. Meanwhile the youngest White British children have contemporaries who are almost 14 per cent Pakistani, but for the over-75s the figure is under 2 per cent. Between the youngest and oldest age groups White British exposure to their own group generally, though occasionally unevenly, increases with age, and their exposure to Pakistanis, and other ethnic minorities, generally decreases with age.

\section{Table 6}

Exposure of White British to own group and other groups (WB $\left.\mathrm{p}^{*} \mathrm{x}\right)$ Wards

\begin{tabular}{|c|c|c|c|c|c|c|}
\hline $\begin{array}{l}\text { Age } \\
\text { groups }\end{array}$ & $\begin{array}{l}\text { White } \\
\text { British }\end{array}$ & $\begin{array}{l}\text { White } \\
\text { Other }\end{array}$ & Indian & Pakistani & Bangladeshi & $\begin{array}{l}\text { All not } \\
\text { White } \\
\text { British }\end{array}$ \\
\hline $0-4$ & 76.3 & 0.7 & 2.2 & 13.9 & 1.5 & 23.7 \\
\hline $5-15$ & 79.7 & 0.6 & 2.2 & 11.5 & 1.1 & 20.3 \\
\hline $16-29$ & 76.7 & 1.3 & 2.8 & 14.0 & 1.3 & 23.3 \\
\hline $30-49$ & 85.0 & 1.4 & 2.4 & 7.1 & 0.5 & 15.0 \\
\hline $50-74$ & 89.8 & 1.7 & 1.6 & 3.8 & 0.3 & 10.2 \\
\hline $75+$ & 92.6 & 3.3 & 0.6 & 1.7 & 0.1 & 7.4 \\
\hline All ages & 83.3 & 1.4 & 2.1 & 8.8 & 0.8 & 16.7 \\
\hline
\end{tabular}

\section{Output areas}

\begin{tabular}{|c|c|c|c|c|c|c|}
\hline $\begin{array}{l}\text { Age } \\
\text { groups }\end{array}$ & $\begin{array}{l}\text { White } \\
\text { British }\end{array}$ & $\begin{array}{l}\text { White } \\
\text { Other }\end{array}$ & Indian & Pakistani & Bangladeshi & $\begin{array}{l}\text { White } \\
\text { British }\end{array}$ \\
\hline $0-4$ & 83.8 & 0.7 & 1.7 & 8.3 & 0.7 & 16.2 \\
\hline 5-15 & 85.7 & 0.7 & 1.7 & 6.8 & 0.5 & 14.3 \\
\hline $16-29$ & 83.7 & 1.4 & 2.3 & 8.4 & 0.6 & 16.3 \\
\hline $30-49$ & 88.1 & 1.4 & 2.0 & 4.7 & 0.3 & 11.9 \\
\hline $50-74$ & 91.8 & 1.6 & 1.3 & 2.5 & 0.2 & 8.2 \\
\hline $75+$ & 94.5 & 2.5 & 0.4 & 1.2 & 0.0 & 5.5 \\
\hline All ages & 87.2 & 1.4 & 1.7 & 5.7 & 0.4 & 12.8 \\
\hline
\end{tabular}


The lower part of the table shows that the White British typically find that over 87 per cent of their output area neighbours are White British. For under-5s the figure is lower, just below 84 per cent, and it generally increases with age to over 94 per cent for the oldest group. At the same time, White British exposure to Pakistanis averages under 6 per cent, and generally decreases from over 8 per cent for under 5 s to just over 1 per cent for the over 75s. White British exposure to other ethnic minorities is very low, but still decreases with age. The lowest figure in the table, 0.0 , indicates that on average White British who are over 75 find that less than one twentieth of 1 per cent (less than 1 in 2000) of the population of their output areas are Bangladeshi. In output areas averaging about 321 people this is quite reasonably rounded to zero.

It may be noted that when the figures in any row of table 6 in the White British column and the 'All not White British' column are added together they amount to 100 per cent. To put it another way, if one’s neighbours are not White British they belong in a separate ethnic group. The ‘All not White British’ figures incorporate the figures for the specific minorities listed in the table, and for the other groups not shown. As with specific minorities the figures in this column generally decrease with age. At wad level the average White British under 5 has neighbours who are almost 24 per cent, nearly a quarter, from other ethnic groups at ward level. For output areas the equivalent is just over 16 per cent, or approaching one sixth. For those over 75 White British chances of finding a neighbour of differing ethnicity fall to somewhat over 7 per cent at ward level, and to under 6 per cent for output areas.

Without examining the relationships shown in the following tables it is premature to make a judgement on the significance of table 6 for the understanding of community cohesion. We may nevertheless observe that for the average member of the White British group in Bradford the experience is of living in areas which are predominantly co-ethnic. Moreover only younger people are likely to find that any specific minority amounts to more than a small proportion of their local co-residents. Experience of a multi-ethnic presence is more visible for the white British when all minorities are considered as a single group.

Exposure to the White British 
Table 6 looked at White British chances of encountering others; table 7 examines the chances of others encountering the White British. The meaning of the White British column remains the same, but the other columns tell a different story. In a city with a 76 per cent White British majority the chances of minorities having White British neighbours are substantially greater than the White British chance of minority neighbours. Thus at ward level White Others find that on average 72 per cent of their neighbours are White British; for Indians the figure is 59 per cent, for Pakistanis over 46 per cent, and for Bangladeshis over 54 per cent. When output areas are considered, the figures become respectively, and approximately, 73 per cent, 50 per cent, 30 per cent and 29 per cent. Thus for White Others the change of scale increases the chances of finding White British neighbours, but for the three South Asian groups it reduces them. Across the two scales we can say that White Others have a chance of White British neighbours approaching that of the White British themselves. Indians have a lower chance, but they are still likely to find over half their neighbours are White British, and for Pakistanis and Bangladeshis the White British make up round about a half of their neighbours at ward scale, but rather less than a third at output area scale.

\section{Table 7}

\section{Exposure to White British (x p* WB)}

\section{Wards}

\begin{tabular}{|c|c|c|c|c|c|c|}
\hline $\begin{array}{l}\text { Age } \\
\text { groups }\end{array}$ & $\begin{array}{l}\text { White } \\
\text { British }\end{array}$ & $\begin{array}{l}\text { White } \\
\text { Other }\end{array}$ & Indian & Pakistani & Bangladeshi & $\begin{array}{l}\text { All not } \\
\text { White } \\
\text { British }\end{array}$ \\
\hline $0-4$ & 76.3 & 64.4 & 46.4 & 30.4 & 37.2 & 36.4 \\
\hline $5-15$ & 79.7 & 70.6 & 51.1 & 35.5 & 44.5 & 42.2 \\
\hline $16-29$ & 76.7 & 56.1 & 52.6 & 39.9 & 47.6 & 44.2 \\
\hline $30-49$ & 85.0 & 78.8 & 63.0 & 48.0 & 57.4 & 56.8 \\
\hline $50-74$ & 89.8 & 84.3 & 67.7 & 59.0 & 68.0 & 69.1 \\
\hline $75+$ & 92.6 & 86.8 & 79.5 & 76.5 & 75.5 & 83.8 \\
\hline All ages & 83.3 & 72.0 & 59.0 & 46.1 & 54.4 & 53.0 \\
\hline
\end{tabular}

\section{Output areas}

\begin{tabular}{|c|c|c|c|c|c|c|}
\hline $\begin{array}{l}\text { Age } \\
\text { groups }\end{array}$ & $\begin{array}{l}\text { White } \\
\text { British }\end{array}$ & $\begin{array}{l}\text { White } \\
\text { Other }\end{array}$ & Indian & Pakistani & Bangladeshi & $\begin{array}{l}\text { All not } \\
\text { White } \\
\text { British }\end{array}$ \\
\hline $0-4$ & 83.8 & 57.6 & 35.6 & 18.2 & 16.6 & 24.7 \\
\hline
\end{tabular}




$\begin{array}{lllllll}\mathbf{5 - 1 5} & 85.7 & 68.3 & 39.7 & 21.0 & 20.2 & 29.6 \\ \mathbf{1 6 - 2 9} & 83.7 & 60.7 & 42.8 & 24.0 & 21.8 & 31.0 \\ \mathbf{3 0 - 4 9} & 88.1 & 78.0 & 53.6 & 31.8 & 34.1 & 45.0 \\ \mathbf{5 0 - 7 4} & 91.8 & 80.3 & 57.2 & 38.1 & 37.3 & 55.8 \\ \mathbf{7 5 +} & 94.5 & 70.2 & 55.4 & 49.5 & 32.6 & 66.8 \\ & & & & & & \\ \text { All ages } & 87.2 & 73.3 & 50.3 & 29.6 & 28.5 & 40.7\end{array}$

When we examine age groups exposure to the White British increases with age for each group at both scales. There is no difference between the White British themselves and minority groups in this regard. This is a difference from table 6 . There we were measuring the exposure of the White British to a series of different groups, but here we are measuring the exposure of several different groups to one group, the White British. Exposure to the White British increases with age because the proportion of White British in the population increases with age. In table 6 however the exposure of the White British to other groups declines with age because these other groups are generally a smaller proportion of successively older groups.

The fact that table 6 measures the exposure of the White British to other groups, whereas table 7 measures the exposure of these other groups to the White British also explains why the White British and 'All not White British' columns in table 7 do not sum to 100. The exposure values of individual 'not White British' groups are not additive components of the final column of the table. The 'All not White British' figures are actually a weighted average of the individual groups (both shown in the table and not shown).

\section{Exposure of Pakistanis}

Tables 8 and 9 are similar to tables 6 and 7, but with Pakistanis, the largest minority group, in place of the White British. Table 8 looks at the exposure of Pakistanis to themselves and to other groups. At ward scale the average Pakistani finds that almost 39 per cent of their neighbours are also Pakistanis, but that these are outnumbered by about 46 per cent of White British. When we switch to the output area scale this relationship is reversed, Pakistanis find that over 54 per cent of their co-residents are also Pakistanis, but only a little under 30 per cent are White British. In table 6 the White British found that they were much more exposed to their own group than to any other group, but here Pakistanis, though experiencing a considerable presence of 
fellow Pakistanis, also have substantial numbers of White British neighbours. In this table, as in table 6, the remaining ethnic groups make little impact.

The age group figures in table 8 show that Pakistani exposure to the White British increases with age. At ward level the White British make up just over 30 per cent of co-residents of a similar age for Pakistanis aged 0-4, but this increases to over 76 per cent for the over 75s. At output area level Pakistani under 5s find that only about 18

\section{Table 8}

Exposure of Pakistanis to own group and other groups (P $\left.\mathbf{p}^{*} \mathbf{x}\right)$

Wards

\begin{tabular}{|c|c|c|c|c|c|c|}
\hline $\begin{array}{l}\text { Age } \\
\text { groups }\end{array}$ & $\begin{array}{l}\text { White } \\
\text { British }\end{array}$ & $\begin{array}{l}\text { White } \\
\text { Other }\end{array}$ & Indian & Pakistani & Bangladeshi & $\begin{array}{l}\text { All not } \\
\text { White } \\
\text { British }\end{array}$ \\
\hline $0-4$ & 30.5 & 0.5 & 3.9 & 54.2 & 1.5 & 23.7 \\
\hline $5-15$ & 35.5 & 0.5 & 4.4 & 49.8 & 1.1 & 20.3 \\
\hline $16-29$ & 39.8 & 1.8 & 4.8 & 44.3 & 1.3 & 23.3 \\
\hline $30-49$ & 48.0 & 1.4 & 5.8 & 36.5 & 0.5 & 15.0 \\
\hline $50-74$ & 59.0 & 2.3 & 6.5 & 25.4 & 0.3 & 10.2 \\
\hline $75+$ & 76.5 & 7.0 & 2.8 & 10.3 & 0.1 & 7.4 \\
\hline All ages & 46.1 & 1.7 & 4.9 & 38.9 & 0.7 & 16.7 \\
\hline
\end{tabular}

\section{Output areas}

\begin{tabular}{|c|c|c|c|c|c|c|}
\hline $\begin{array}{l}\text { Age } \\
\text { groups }\end{array}$ & $\begin{array}{l}\text { White } \\
\text { British }\end{array}$ & $\begin{array}{l}\text { White } \\
\text { Other }\end{array}$ & Indian & Pakistani & Bangladeshi & $\begin{array}{l}\text { All not } \\
\text { White } \\
\text { British }\end{array}$ \\
\hline $0-4$ & 18.1 & 0.5 & 3.8 & 66.7 & 4.5 & 81.8 \\
\hline $5-15$ & 21.0 & 0.5 & 4.8 & 64.1 & 3.6 & 79.0 \\
\hline $16-29$ & 23.0 & 1.2 & 5.1 & 60.2 & 3.5 & 76.0 \\
\hline $30-49$ & 31.8 & 1.2 & 6.2 & 51.9 & 2.3 & 68.3 \\
\hline $50-74$ & 38.1 & 2.4 & 7.4 & 44.6 & 2.3 & 61.9 \\
\hline $75+$ & 49.5 & 9.2 & 3.0 & 34.2 & 0.9 & 50.5 \\
\hline All ages & 29.6 & 1.4 & 5.3 & 54.4 & 3.1 & 70.5 \\
\hline
\end{tabular}

per cent of their local contemporaries are White British, but for Pakistanis over 75 the figure is almost 50 per cent. Pakistanis' exposure to their own group behaves in the opposite way to their exposure to the White British at both scales: it falls with age, reflecting their successively lower proportions in successive age cohorts. Thus at ward 
level the youngest age group finds just over 54 per cent self exposure, but at output area scale average under-5 Pakistanis have nearly 67 per cent co-ethnic contemporaries. For the oldest Pakistanis exposure to one's own group is much lower, only just over 10 per cent at ward scale, and about 34 per cent at the output area level. In general it may be seen that for Pakistanis in younger age groups more of their contemporaries are Pakistani rather than White British, but for older Pakistanis the opposite is the case. This applies at both scales, but only the over-75s experience a White British plurality more locally, while it applies to those aged 30 or older at the ward scale.

\section{Exposure to Pakistanis}

In table 9 exposure to Pakistanis is assessed. The figures for Pakistanis are of course as in table 8. For the White British the figures are a repeat of those in the Pakistani column of table 6. So Pakistani self-exposure can be seen to be several times higher than White British exposure to Pakistanis at both scales, and both sets of values decline with age. The new elements of this table are the figures for the exposure of other minorities to Pakistanis. For White Others exposure to Pakistanis falls from about 17 per cent for wards to about 14 per cent for output areas. In contrast, for

\section{Table 9}

\section{Exposure to Pakistanis (x p* $\mathbf{P})$}

\section{Wards}

\begin{tabular}{|c|c|c|c|c|c|c|}
\hline $\begin{array}{l}\text { Age } \\
\text { groups }\end{array}$ & $\begin{array}{l}\text { White } \\
\text { British }\end{array}$ & $\begin{array}{l}\text { White } \\
\text { Other }\end{array}$ & Indian & Pakistani & Bangladeshi & $\begin{array}{l}\text { All not } \\
\text { White } \\
\text { British }\end{array}$ \\
\hline $0-4$ & 13.9 & 23.2 & 37.9 & 54.2 & 46.1 & 48.5 \\
\hline 5-15 & 11.5 & 19.2 & 33.5 & 49.8 & 39.8 & 43.3 \\
\hline $16-29$ & 14.0 & 28.6 & 31.7 & 44.3 & 36.2 & 40.1 \\
\hline $30-49$ & 7.1 & 11.7 & 22.6 & 36.5 & 28.0 & 29.0 \\
\hline $50-74$ & 3.8 & 7.3 & 18.2 & 25.4 & 18.2 & 17.9 \\
\hline $75+$ & 1.7 & 4.2 & 8.1 & 10.3 & 10.2 & 6.0 \\
\hline All ages & 8.8 & 17.3 & 26.6 & 38.9 & 30.6 & 32.8 \\
\hline
\end{tabular}

\section{Output areas}

Age groups
White White Other
Indian 


$\begin{array}{lcccccc} & \text { British } & & & & & \text { British } \\ \mathbf{0 - 4} & 8.3 & 18.7 & 37.4 & 66.7 & 49.4 & 56.8 \\ \mathbf{5 - 1 5} & 6.8 & 15.7 & 35.6 & 64.1 & 46.8 & 53.0 \\ \mathbf{1 6 - 2 9} & 8.4 & 18.2 & 34.0 & 60.2 & 46.3 & 50.8 \\ \mathbf{3 0 - 4 9} & 4.7 & 9.7 & 24.0 & 51.9 & 41.9 & 37.9 \\ \mathbf{5 0 - 7 4} & 2.5 & 7.5 & 20.1 & 44.6 & 33.0 & 27.2 \\ \mathbf{7 5 +} & 1.2 & 6.1 & 8.4 & 34.2 & 18.1 & 33.3 \\ & & & & & & \\ \text { All ages } & 5.7 & 14.2 & 28.7 & 54.4 & 42.3 & 45.9\end{array}$

Indians, Bangladeshis, and the 'not White British' collectively, exposure increases as we move from wards to output areas. The Indian figures are lower than those for Bangladeshis at both scales, and both are lower than the collective figures. The higher level of collective exposure to Pakistanis is explained by their incorporation of the self-exposure experience of the relatively large Pakistani community. The effect of age on these values is negative; that is exposure declines as age increases at both scales. Two exceptional features of the age group results occur for the two oldest age groups for White Others, and for the youngest Indians. The older White Others are slightly more exposed to Pakistanis across output areas than across wards, unlike other White Other age groups. The youngest Indians are slightly less exposed to Pakistanis for output areas than they are for wards, unlike other Indian cohorts.

\section{Exposure to Own Group}

Table 10 presents the final set of results the self-exposure of each the ethnic groups. We have already seen the White British and Pakistani data. Here the higher figures for the White British are apparent for all age groups, and at both scales. The increase in self-exposure with age for the White British can be contrasted with the Pakistani experience, where self-exposure declines with age. We can also see that self-exposure increases for both groups as we switch from wards to output areas. This also applies to the other ethnic groups in the table, figures which are not reported previously. At both scales however the White Other figures are very low, indicating that members of this group generally live in areas dominated by other groups. The other group of similar size, Bangladeshis, also have very low self-exposure at ward level, but the figure increases to about 18 per cent for output areas. This suggests a group somewhat clustered in particular parts of several different wards. Indian self-exposure is low at ward level, and remains modest for output areas. For the 'not White British' aggregate category self-exposure is however quite substantial. If you are not White 
British you find that 47 per cent of your neighbours at ward level are also thus classifiable, and for output areas the figure increases to about 59 per cent.

The impacts of age on self-exposure are uneven. As for the White British and Pakistanis values decrease with age for 'All not White British' at both scales, and for Bangladeshis at ward scale. For Bangladeshis across output areas however selfexposure increases in both directions from a minimum in the 30-49 age band. This

\section{Table 10}

Exposure to own group $\left(\mathrm{x} \mathrm{p}^{*} \mathrm{x}\right)$

Wards

\begin{tabular}{|c|c|c|c|c|c|c|}
\hline $\begin{array}{l}\text { Age } \\
\text { groups }\end{array}$ & $\begin{array}{l}\text { White } \\
\text { British }\end{array}$ & $\begin{array}{l}\text { White } \\
\text { Other }\end{array}$ & Indian & Pakistani & Bangladeshi & $\begin{array}{l}\text { All not } \\
\text { White } \\
\text { British }\end{array}$ \\
\hline $0-4$ & 76.3 & 0.9 & 4.9 & 54.2 & 6.0 & 63.6 \\
\hline $5-15$ & 79.7 & 0.7 & 5.5 & 49.8 & 4.7 & 57.8 \\
\hline $16-29$ & 76.7 & 2.5 & 5.7 & 44.3 & 4.4 & 55.8 \\
\hline $30-49$ & 85.0 & 1.6 & 6.0 & 36.5 & 2.1 & 43.1 \\
\hline $50-74$ & 89.8 & 2.1 & 6.2 & 25.4 & 1.7 & 30.9 \\
\hline $75+$ & 92.6 & 5.3 & 2.8 & 10.3 & 0.6 & 16.2 \\
\hline All ages & 83.3 & 1.7 & 5.3 & 38.9 & 3.2 & 47.0 \\
\hline
\end{tabular}

\section{Output areas}

\begin{tabular}{|c|c|c|c|c|c|c|}
\hline $\begin{array}{l}\text { Age } \\
\text { groups }\end{array}$ & $\begin{array}{l}\text { White } \\
\text { British }\end{array}$ & $\begin{array}{l}\text { White } \\
\text { Other }\end{array}$ & Indian & Pakistani & Bangladeshi & $\begin{array}{l}\text { All not } \\
\text { White } \\
\text { British }\end{array}$ \\
\hline $0-4$ & 83.8 & 13.3 & 17.2 & 66.7 & 24.0 & 75.3 \\
\hline $5-15$ & 85.7 & 7.0 & 14.7 & 64.1 & 23.7 & 70.4 \\
\hline $16-29$ & 83.7 & 7.9 & 13.7 & 60.2 & 21.7 & 69.0 \\
\hline $30-49$ & 88.1 & 4.1 & 13.9 & 51.9 & 14.8 & 55.0 \\
\hline $50-74$ & 91.8 & 6.0 & 15.1 & 44.6 & 18.1 & 44.2 \\
\hline $75+$ & 94.5 & 19.6 & 25.2 & 34.2 & 26.7 & 37.2 \\
\hline All ages & 87.2 & 3.0 & 11.8 & 54.4 & 18.2 & 59.3 \\
\hline
\end{tabular}

feature is replicated for the Indian output area results, but with the minimum among those aged 30-49. On the ward scale Indian self-exposure declines in both directions from an admittedly low maximum among 50-74 year-olds. For White Others there is a minimum among those aged 30-49 for output areas, and a totally random pattern at 
ward level. Explanations for these variations may lie in the detailed history of immigration, settlement and relocation of the different age bands within these ethnic groups. For White Others for example the figures for older ages may be related to refugee immigration from eastern Europe in the late 1940s and early 1950s, while for younger ages migration from the same area following the collapse of the iron curtain may be significant. At intermediate ages both the children of the former group, and migrants from other countries may be significant.

\section{Conclusion}

This paper addresses a very general question: do age divisions exacerbate the significance of ethnic segregation? The question arose from the very specific context of a riot in one city, and has been explored on the basis of demographic data from that city. In order to answer the general question we need to ask whether Bradford is in any way atypical, and the answer to this is that it might be. The city has the highest proportion of Pakistanis of any local authority in the United Kingdom, and because of the numerical dominance of the White British and Pakistanis in the city, it is less diverse in its ethnicity than many London Boroughs and several other cities and towns such as Leicester, Birmingham, Manchester and Luton. It is however reasonable to see Bradford as part of a continuum of ethnic profiles rather than one which is different by an order of magnitude. So it may be fair to infer that the effects of age on segregation in Bradford are likely to recur elsewhere in the country, but not necessarily to the same degree.

An overall summary of the situation we have examined might be that the multicultural experience in Bradford is more apparent to members of ethnic minorities than it is to the White British, but that this experience is modified, but not necessarily exacerbated by age. The average White British person lives in an environment which is very much dominated by their own group, and this applies even more on the very local scale than it does at ward level. For most ethnic minorities however the average experience is of living in localities where the White British are either numerically dominant or a considerable presence. On average only Pakistanis find themselves more numerous in their vicinity than the White British, and this only applies to some age groups at both spatial levels. The two youngest Bangladeshi age groups also outnumber the White 
British at output area level, but the main interethnic exposure of Bangladeshis is to Pakistanis, particularly among younger people.

The modification of the experience of exposure to other ethnic groups according to age is sometimes to increase it, but also sometimes to decrease it. Among the White British younger people have a greater chance of interethnic exposure, and therefore of potential contact. Among Pakistanis the chances of interethnic exposure are generally higher than for the White British, but they are higher for older Pakistanis than younger. This is entirely a consequence of greater exposure to the white British. The exposure of other minorities to the White British also increases with age. Exposure to Pakistanis decreases with age for these groups.

We can perhaps draw some tentative conclusions on the relevance of ethnic separation, and the presumed decrease in community cohesion, for the explanation of Bradford's main 2001 riot. The most numerous participants were young Pakistanis and we have seen that the self-exposure of the 16-29 Pakistani age group was over 60 per cent for output areas. Exposure to the White British was only 23 per cent. Opportunities for familiarity with neighbours across the ethnic divide were therefore limited.

But segregation alone cannot fully explain why the riot broke out. The reasons identified by Alexander (2005) may have been more fundamental, but segregation may have amplified their impact. If you are unemployed or underemployed, and have experienced discrimination, the feeling of being separate from the majority of society cannot contribute to harmonious relations. Moreover it is clear that the savage confrontation with the police that was the core event of the Bradford disturbances, and resulted in most of the arrests and heavy sentences, broke out at precisely the place the city centre ended and Pakistani residential space began. Having been directed away from the city centre by police manoeuvres young Pakistanis became more aggressive as 'their' territory was entered by the police.

To the extent that lack of inter-group ethnic contacts contributed to the riot we cannot be optimistic about the future. For those too young to have participated in the riot the indications of ethnic separation in the preceding tables are greater than for the rioters' age group. Moreover the younger South Asian age groups are larger. This doesn't 
guarantee a recurrence of the disturbances because other factors may have changed, but it does not help.

It may have been noticed that the index of dissimilarity has been ignored in this concluding discussion. The technical inadequacy of the measure when applied to many small areas and to small population sub-groups is one reason for this. The main reason however is that the asymmetrical experiences incorporated in the various exposure measures is much more helpful in understanding segregation means.

This paper has by no means exhausted the possibilities of analysing the interaction of age and segregation. Quite apart from the multiplicity of other cities and other ethnic patterns that could be examined there are also other technical possibilities within exposure techniques. First the census's intermediate scale of super output areas might be examined. Secondly a more thorough consideration could be given to interminority relations. Third, since the index values quoted here have all been citywide, it would be possible to take a closer look at the situation in specific parts of the city. The experience in inner city zones will clearly be different from in the most peripheral suburbs. Finally, and perhaps most productively, the analysis could be extended to relations between age groups across the ethnic divide.

\section{Bibliography}

Alexander, C. 2005, 'Embodying Violence: "Riots”, Dis/Order and the Private Lives of "the Asian Gang”', in C. Alexander \& C. Knowles (eds), Making Race Matter: Bodies, Space and Identity, Palgrave Macmillan, Basingstoke, pp. 199-217.

Allen, C. 2003, Fair Justice: the Bradford Disturbances, the Sentencing and the Impact, Forum Against Islamophobia and Racism, London.

Amin, A. 2003, 'Unruly Strangers? The 2001 Urban Riots in Britain', International Journal of Urban and Regional Research, vol. 27, no. 2, pp. 460-463.

Burgess, S. \& Wilson, D. 2003, Ethnic Segregation in England's Schools, CMPO Working Paper 03/086, Centre for Market and Public Organisation, University of Bristol, Bristol.

Fortier, A.-M. 2007, 'Too Close for Comfort: Loving thy Neighbour and the Management of Multicultural Intimacies', Environment and Planning D: Society and Space, vol. 25, no. 1, pp. 104-119.

Home Office 2001a, Building Cohesive Communities: A Report of the Ministerial Group on Public Order and Community Cohesion (The Denham Report), Home Office, London.

Home Office 2001b, Community Cohesion: A Report of the Independent Review Team, The Cantle Report, Home Office, London. 
Husan, R. 2003, 'Critical Remarks on Cultural Aspects of Asian Ghettos in Modern Britain', Capital \& Class, no. 81, pp. 103-133.

Jackson, P. 1992, 'The Racialization of Labour in Post-war Bradford', Journal of Historical Geography, vol. 18, no. 2, pp. 190-209.

Johnston, R., Wilson, D. \& Burgess, S. 2004, 'School Segregation in Multiethnic England', Ethnicities, vol. 4, no. 2, pp. 237-265.

Kundnani, A. 2001, 'From Oldham to Bradford: the Violence of the Violated', Race \& Class, vol. 43, no. 2, pp. 105-110.

McEvoy, D. 2007, 'Community Cohesion and the 2001 Riots in the North of England', paper presented to the $12^{\text {th }}$ International Metropolis Conference, Melbourne.

McGhee, D. 2003, 'Moving to “our” Common Ground - a Critical Examination of Community Cohesion Discourse in Twenty-first century Britain', Sociological Review, vol. 51, no. 3, pp. 383-411.

Ouseley, H. 2001, Community Pride not Prejudice, Making Diversity Work in Bradford, Bradford Vision, Bradford.

Peach, C. \& Rossiter, D. 1996, 'Level and Nature of Spatial Concentration of Minority Ethnic Populations in Great Britain, 1991', in P. Ratcliffe (ed.), Ethnicity in the 1991 Census, Volume Three: Social Geography and Ethnicity in Britain: Geographical Spread, Spatial Concentration and Internal Migration, HMSO, London, pp. 111-134.

Renton, D. 2003, 'Examining the Success of the British National Party, 1999-2003', Race \& Class, vol. 45, no. 2, pp. 75-85.

Simpson, L. 2004, 'Statistics of Racial Segregation: Measures, Evidence and Policy', Urban Studies, vol. 41, no. 3, pp. 661-681.

Webster, C. 2003, 'Race, Space and Fear: Imagined Geographies of Racism, Crime, Violence and Disorder in Northern England', Capital \& Class, no. 80, pp. 95122. 